\title{
Asymptomatic Paget's disease of bone in a 62-year-old Nigerian man: three years post-alendronate therapy
}

\author{
Clement Olukayode Aransiola and Arinola Ipadeola ${ }^{1}$
}

Department of Medicine, LAUTECH Teaching Hospital, Ogbomoso, Nigeria

${ }^{1}$ Department of Medicine, University College Hospital, Ibadan, Nigeria

Corresponence should be addressed to C O Aransiola Email aransiolak@yahoo.com

\section{Summary}

Paget's disease is a chronic and progressive disorder of bone characterized by focal areas of excessive osteoclastic resorption accompanied by a secondary increase in the osteoblastic activity. Paget's disease of bone (PBD) is a rare endocrine disease especially among Africans and Asians. Hence the detection of a case in a middle-aged Nigerian is of interest. We present the case of a 62-year-old Nigerian man in apparent good health who was found to have a markedly elevated serum total alkaline phosphatase (ALP) of $1179 \mathrm{U} / \mathrm{l}$ (reference range, 40-115 U/l) 4 years ago during a routine medical check-up in the USA. He had no history suggestive of PDB and also had no known family history of bone disease. Examination findings were not remarkable except for a relatively large head. A repeat ALP in our centre was $902 \mathrm{U} / \mathrm{l}$ (reference range, 40-120 U/I). Cranial CT scan showed diffuse cranial vault thickening consistent with Paget's disease which was confirmed by Tc-99m hydroxymethylene diphosphonate. He was placed on $40 \mathrm{mg}$ alendronate tablets daily for 6 months. The patient has remained asymptomatic and has been in continuing biochemical remission during the 3-year follow-up period. The most recent ALP result is $88 \mathrm{U} / \mathrm{l}$ (reference range, 30-132 U/l) in April 2015.

\section{Learning points:}

- Serum total alkaline phosphatase remains a sensitive marker of bone turnover and an isolated increase above the upper limit of normal warrants more intense scrutiny in form of investigations targeted at excluding PD.

- Paget's disease is very rare but can occur in the Africans as seen in this Nigerian man and most patients are asymptomatic.

- Asymptomatic patients can benefit from treatment if disease is active, polyostotic or the lesions are located in bones with future risk of complications such as long bones, vertebrae and skull.

- Bisphosphonates are still the mainstay of treatment and alendronate is a useful therapeutic option for treatment.

\section{Background}

Paget's disease is a chronic and progressive disorder of bone characterized by focal areas of excessive osteoclastic resorption accompanied by a secondary increase in the osteoblastic activity (1). PDB is a rare endocrine disease and the detection of a case in a Nigerian is of interest because it is about 45 years now since Bohrer reported five cases of Paget's disease in more than 20000 Nigerians studying at the Radiology Department of the University College Hospital, Ibadan. Though studies from other subSaharan countries still support the rarity of Paget's disease Dahniya reported that 14 cases of Paget's disease were seen in an African community over a 4-year period (1978-1982) (2). During a comparable 4-year period, no case of Paget's disease 
was seen in a busy radiology department of a large teaching hospital in Nigeria (2). The fact that the incidence and the severity of Paget's disease is decreasing in some countries which were hitherto hotbeds of PDB also makes it all the more important to highlight this case. For a disease whose presentation is largely without symptoms clinicians need to exercise a high index of suspicion especially in the sub-Saharan Africa where access to quality health care delivery is still beyond the reach of the common man.

\section{Case presentation}

A 62-year-old male Nigerian who has been in apparent good health was found to have markedly elevated serum alkaline phosphatase (ALP) of $1179 \mathrm{U} / 1$ (reference range, 40-115 U/1) (Table 1) during a routine medical check-up early in 2011 in the USA. He presented to the University College Hospital, Ibadan, Nigeria, in October 2011 and was referred to the endocrine unit in November of the same year with a diagnosis of PDB. He had no history of joint or bone pains, deafness, tinnitus, dental malocclusion, fractures, excessive heat or body weakness. He had not noticed any abnormal enlargement of the bones of his body including that of the head though he admitted to the fact that his head had always been a bit larger than that of others. There was no increase in his hat size in the last 20 years and also had no history of contact with domestic animals. He had no history referable to the

Table 1 Initial metabolic work-up.

\begin{tabular}{|c|c|c|}
\hline Parameter & Result & Reference range \\
\hline Glucose & 80 & $65-99 \mathrm{mg} / \mathrm{dl}$ \\
\hline BUN & 15 & $7-25 \mathrm{mg} / \mathrm{dl}$ \\
\hline Creatinine & 1.09 & $0.76-1.46 \mathrm{mg} / \mathrm{dl}$ \\
\hline eGFR African American & 86 & $>0 \mathrm{ml} / \mathrm{min}$ per 1.73 \\
\hline eGFR non-African American & 74 & $>60 \mathrm{ml} / \mathrm{min}$ per 1.73 \\
\hline Calculated BUN/creatinine & 13.8 & $6-22$ ratio \\
\hline Sodium & 140 & 135-146 mmol/l \\
\hline Potassium & 4.2 & $3.5-5.3 \mathrm{mmol} / \mathrm{l}$ \\
\hline Chloride & 104 & $98-110 \mathrm{mmol} / \mathrm{l}$ \\
\hline Carbon dioxide & 22 & $21-33 \mathrm{mmol} / \mathrm{l}$ \\
\hline Calcium & 9.6 & $8.6-10.2 \mathrm{mg} / \mathrm{dl}$ \\
\hline Protein, total & 6.9 & $6.2-8.3 \mathrm{~g} / \mathrm{dl}$ \\
\hline Albumin & 4.4 & $3.6-5.1 \mathrm{~g} / \mathrm{dl}$ \\
\hline Calculated globulin & 2.5 & $2.1-3.7 \mathrm{~g} / \mathrm{dl}$ \\
\hline Calculated A/G ratio & 1.8 & $1.0-2.1$ ratio \\
\hline Bilirubin, total & 0.6 & $0.2-1.2 \mathrm{mg} / \mathrm{dl}$ \\
\hline Alkaline phosphatase & 1179 & $40-115 \mathrm{U} / \mathrm{I}$ \\
\hline SGOT (AST) & 28 & $10-35 \mathrm{U} / \mathrm{l}$ \\
\hline SGPT (ALT) & 27 & $9-60 \mathrm{U} / \mathrm{l}$ \\
\hline
\end{tabular}

BUN, blood urea nitrogen.
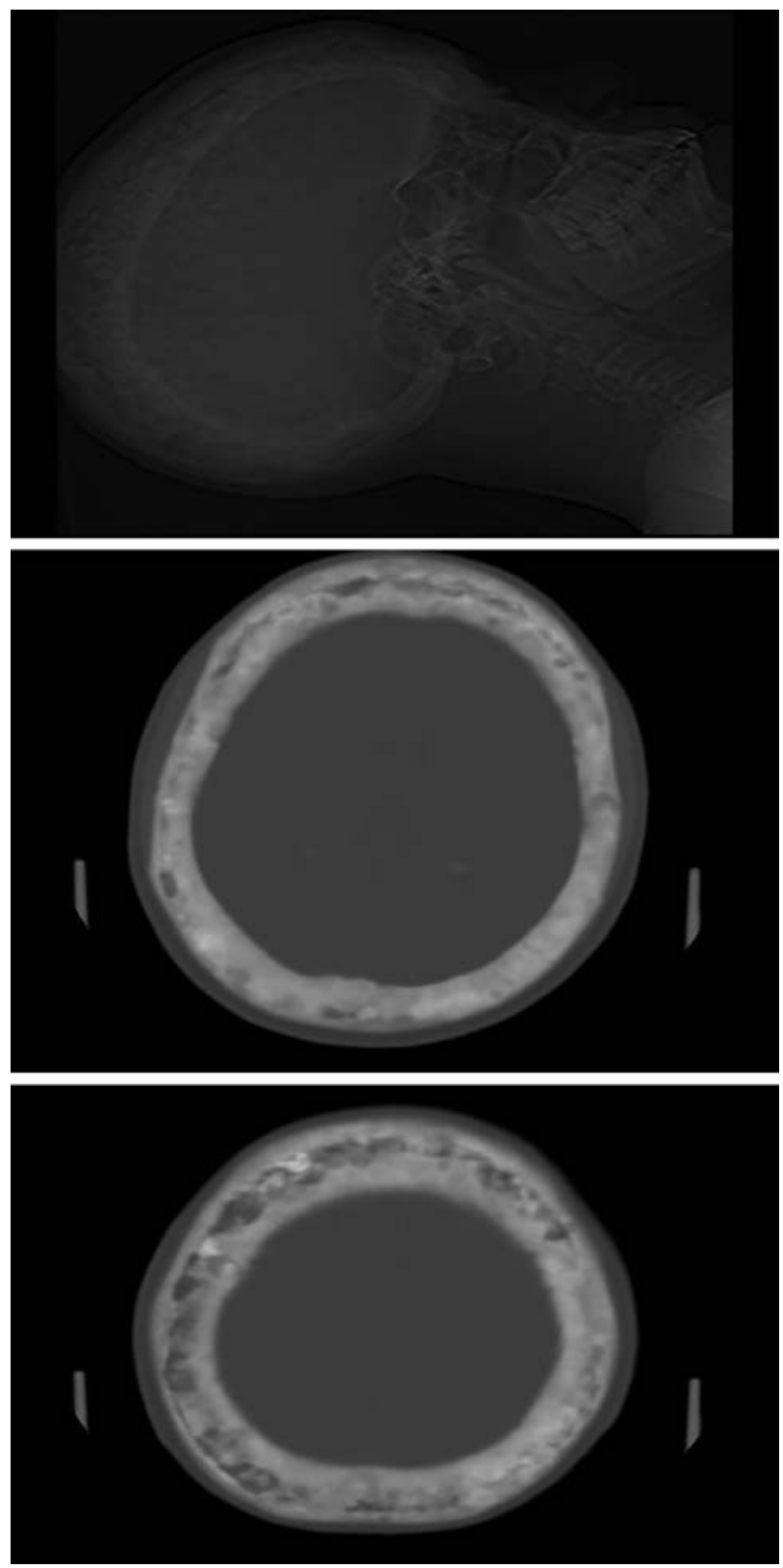

Figure 1

Cranial CT scan showing diffuse cranial vault thickening consistent with PD.

cardiovascular system. The past medical history is 'Nil' of note. He is married in a monogamous relationship with children. He has no known family history of bone disease. Cardiovascular system examination revealed a pulse of 68 beats/min, it was regular and of normal volume; his blood pressure was 100/60 $\mathrm{mmHg}$; and the remainder of cardiovascular system examination was within the normal limits. His respirations were 16 breaths/min and breath sounds were vesicular. Examination of the musculoskeletal system revealed an enlarged head 


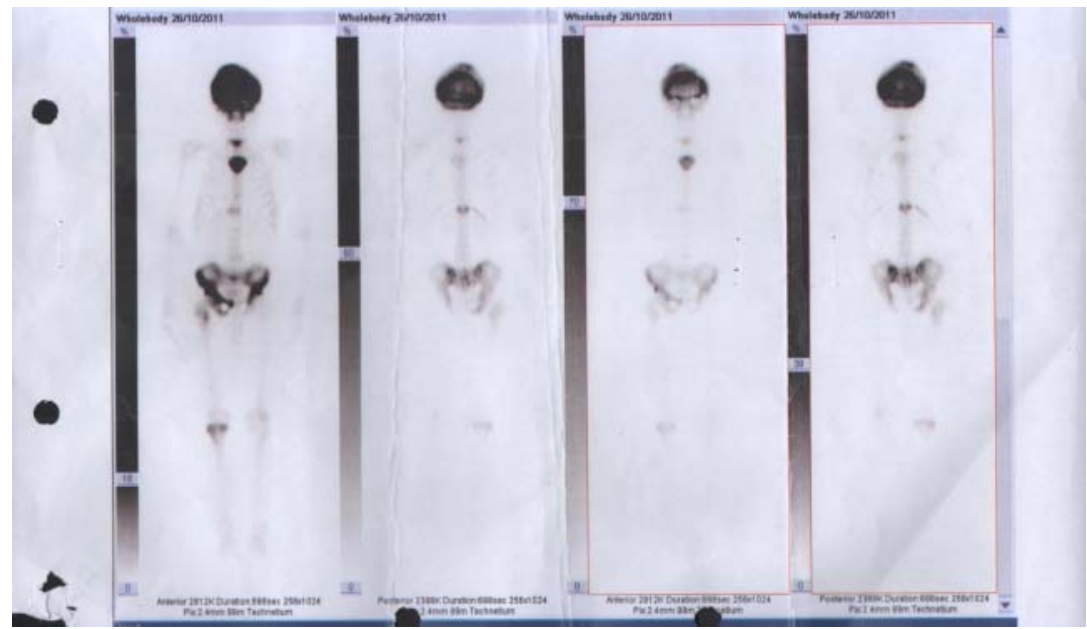

Figure 2

Tc-99m HMDP bone scan showing uptake in the skull, spine, sternum, the ribs, pelvis, right femur and tibia.

otherwise is not remarkable. CNS examination was essentially normal.

\section{Investigation}

Repeat liver enzymes at University College Hospital also showed markedly elevated ALP of $902 \mathrm{U} / 1$ (reference range, 40-120 U/1). Cranial CT scan (Fig. 1) showed diffuse cranial vault thickening consistent with Paget's disease which was confirmed by Tc-99m hydroxymethylene diphosphonate (HMDP) bone scan (Fig. 2). Tc-99m HMDP scan showed increased uptake in the skull, spine, sternum, pelvis and right femur and tibia.

\section{Treatment}

He was treated with oral alendronate with combined oral vitamin $\mathrm{D}$ and calcium supplements. A repeat ALP after a 3-month course of oral alendronate was $119 \mathrm{U} / \mathrm{l}$ (reference range, 40-120 U/1). He completed 6 months of alendronate and the ALP subsequently normalized, $78 \mathrm{U} / 1$ (reference range, 40-120 U/1).

\section{Outcome and follow-up}

The patient has been followed up for more than 3 years. He has achieved continuing biochemical remission during this period and has remained asymptomatic. The most recent serum ALP result is $88 \mathrm{U} / 1$ (reference range, 30-132 U/l) (Table 2) in April 2015. A recent plain radiograph of the skull (Fig. 3) showed radiologic healing.

\section{Discussion}

This present patient highlights a case of Paget's disease that has come to light as a result of an isolated markedly elevated serum ALP found on a routine health check-up (Table 1). Paget's disease is rare among Africans and Asians though said to be common in people of European descent (3). Data regarding the prevalence of PDB showed a high prevalence of $1.3 \%$ in the South Africans of African descent, though still lower than a prevalence of $2.4 \%$ among the South Africans of European descent (4).

Table 2 Latest metabolic work-up.

\begin{tabular}{l}
\hline Parameter \\
\hline Glucose \\
BUN \\
Creatinine \\
eGFR African American \\
eGFR non-African American \\
Calculated BUN/creatinine \\
Sodium \\
Potassium \\
Chloride \\
Carbon dioxide \\
Calcium \\
Protein, total \\
Albumin \\
Calculated globulin \\
Calculated A/G ratio \\
Bilirubin, total \\
Alkaline phosphatase \\
SGOT (AST) \\
SGPT (ALT)
\end{tabular}

\begin{tabular}{cll}
\cline { 1 - 1 } Result & & Reference range \\
\cline { 1 - 1 } 77 & & $65-100 \mathrm{mg} / \mathrm{dl}$ \\
13 & & $8-25 \mathrm{mg} / \mathrm{dl}$ \\
1.0 & & $0.8-1.4 \mathrm{mg} / \mathrm{dl}$ \\
92 & & $>60 \mathrm{ml} / \mathrm{min}$ per 1.73 \\
76 & & $>60 \mathrm{ml} / \mathrm{min}$ per 1.73 \\
13 & & $6-28 \mathrm{ratio}$ \\
142 & & $133-146 \mathrm{mmol} / \mathrm{l}$ \\
4.6 & & $3.5-5.3 \mathrm{mmol} / \mathrm{l}$ \\
104 & & $97-110 \mathrm{mmol} / \mathrm{l}$ \\
28 & & $18-30 \mathrm{mmol} / \mathrm{l}$ \\
9.7 & & $8.5-10.5 \mathrm{mg} / \mathrm{dl}$ \\
7.2 & & $6.0-8.4 \mathrm{~g} / \mathrm{dl}$ \\
4.7 & & $2.9-5.0 \mathrm{~g} / \mathrm{dl}$ \\
2.5 & & $2.0-3.8 \mathrm{~g} / \mathrm{dl}$ \\
1.9 & & $0.9-2.5 \mathrm{ratio}$ \\
0.7 & & $0.1-1.3 \mathrm{mg} / \mathrm{dl}$ \\
88 & $30-132 \mathrm{U} / \mathrm{l}$ \\
27 & $5-35 \mathrm{U} / \mathrm{l}$ \\
37 & $7-56 \mathrm{U} / \mathrm{l}$ \\
\hline
\end{tabular}

BUN, blood urea nitrogen 

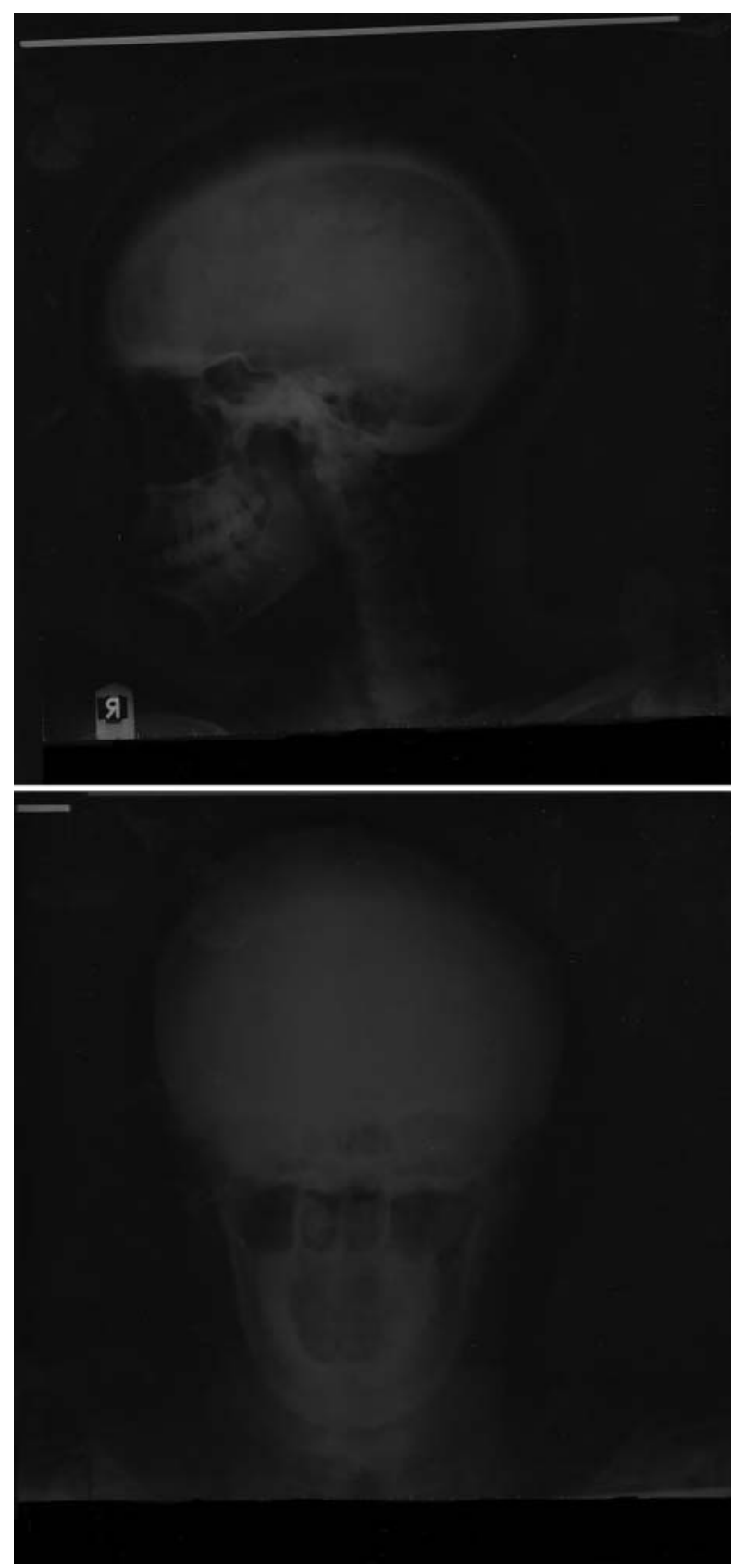

Figure 3

X-ray of skull consistent with radiologic healing post alendronate therapy.

However, the incidence of PDB as well as severity of disease seen by clinicians in some countries which were hitherto hotbeds of PDB is said to be on the decrease (3). PDB is said to be commoner in the older people usually above age 55, thus the age of this patient at diagnosis is in keeping as well as his gender. It is interesting to note that the patient has been asymptomatic of Paget's disease; existing data suggest between 30 and 40\% (5) of patients are symptomatic. The patient was diagnosed with Paget's disease after cranial CT and Tc-99m HMDP scan confirmed the presence of pagetic bones. Guidelines for initiating therapy in patients with PDB also take into cognizance asymptomatic patients who have active disease especially polyostotic lesions (6). Some clinicians are of the school of thought that treatment could reduce the future risk of complications such as nerve compression, bone deformity or fractures in such individuals. He was treated with alendronate which is a potent aminobisphosphonate that has shown proven efficacy and safety in achieving continuing biochemical remission and healing of lytic lesions on bone biopsy in Paget's disease (1) (7) (8). It is interesting to know that his ALP was tenfold the upper limit of the reference range (Table 1) prior to the treatment however, within 3 months a remarkable drop in serum ALP was achieved with oral alendronate. The decision to continue therapy for an additional 3 months is a wellinformed one because serum ALP not only normalized (Table 2) subsequently but this patient has maintained continuing biochemical remission (9) for more than 3 years now. Though serum C-telopeptide or fasting urine N-telopeptide/creatinine which could reveal early reactivation of $\mathrm{PDB}$ was not done it is still safe to assume that this present patient fulfils the criteria for a biochemical remission because serum total ALP is one of the most sensitive markers of bone turnover, secondly only to bone specific ALP with sensitivity of 74 and $84 \%$ respectively (6) (10). Existing literatures elucidate some factors that help in inducing remissions and achieving longer duration of remissions with bisphosphonates to include pre-therapy levels of ALP and post-therapy ALP nadir (9). Siris et al. (7) in a comparative study found that alendronate was superior to etidronate in the treatment of PDB. In that study, after 6 months of oral treatment with $40 \mathrm{mg}$ of alendronate daily there was normalization of ALP in $63 \%$ of the patients, compared with $17 \%$ after treatment with $400 \mathrm{mg}$ etidronate daily (7). However, this is a class effect that has been reported with some other second- and third-generation bisphosphonates. In a recent study, Tucci (9) reported a single intravenous dose of zoledronic acid can induce long-term remissions even in patients who have been previously resistant to other bisphosphonates. Some of the subjects in that study had remission for up to 60 months (9). There are no studies yet to support whether the treatment of asymptomatic patients with Paget's disease with subsequent normalization of ALP actually reduced the complications in the long run. However, this patient's most recent plain radiograph of the skull supports 
the notion that alendronate improves lytic lesions on bone because he also achieved radiologic healing (Fig. 3) (8).

\section{Declaration of interest}

The authors declare that there is no conflict of interest that could be perceived as prejudicing the impartiality of the research reported.

\section{Funding}

This research did not receive any specific grant from any funding agency in the public, commercial, or not-for-profit sector.

\section{Patient consent}

A written informed consent has been obtained from the patient.

\section{Author contribution statement}

C O Aransiola and I Ipadeola are the patient's physicians and are both involved in the writing and review of this manuscript.

\section{Acknowledgements}

The authors are grateful to A A Adeolu, T O Ogundiran, A Akere and O A Ogunlade who were at one point or the other involved in the evaluation of this patient.

\section{References}

1 Walsh JP, Ward LC, Stewart GO, Will RK, Criddle RA, Prince RL, Stuckey BG, Dhaliwal SS, Bhagat CI, Retallack RW et al. 2004 A randomized clinical trial comparing oral alendronate and intravenous pamidronate for the treatment of Paget's disease of bone. Bone 34 747-754. (doi:10.1016/j.bone.2003.12.011)

2 Dahniya MH 1987 Paget's disease of bone in Africans. British Journal of Radiology 60 (710) 113-116. (doi:10.1259/0007-1285-60710-113)

3 Corral-Gudino L, Borao-Cengotita-Bengoa M, Del Pino-Montes J \& Ralston S 2013 Epidemiology of Paget's disease of bone: a systematic review and meta-analysis of secular changes. Bone 55 347-352. (doi:10.1016/j.bone.2013.04.024)

4 Guyer PB \& Chamberlain AT 1988 Paget's disease of bone in South Africa. Clinical Radiology 39 51-52. (doi:10.1016/S0009-9260 (88)80341-6)

5 Meunier PJ, Salson C, Mathieu L, Chapuy MC, Delmas P, Alexandre C \& Charhon S 1987 Skeletal distribution and biochemical parameters of Paget's disease. Clinical Orthopaedics and Related Research 217 37-44.

6 Selby PL, Davie MW, Ralston SH \& Stone MD 2002 Guidelines on the management of Paget's disease of bone. Bone 31 366-373. (doi:10.1016/ S8756-3282(02)00817-7)

7 Siris E, Weinstein RS, Altman R, Conte JM, Favus M, Lombardi A, Lyles K, McIlwain H, Murphy WA, Jr, Reda C et al. 1996 Comparative study of alendronate versus etidronate for the treatment of Paget's disease of bone. Journal of Clinical Endocrinology and Metabolism 81 961-967. (doi:10.1210/jcem.81.3.8772558)

8 Reid IR, Nicholson GC, Weinstein RS, Hosking DJ, Cundy T, Kotowicz MA, Murphy WA, Jr, Yeap S, Dufresne S, Lombardi A et al. 1996 Biochemical and radiologic improvement in Paget's disease of bone treated with alendronate: a randomized, placebocontrolled trial. American Journal of Medicine 101 341-348. (doi:10.1016/S0002-9343 (96)00227-6)

9 Tucci JR 2015 Zoledronic acid therapy of patients with Paget disease of bone resistant to or with unsustained remission following prior bisphosphonate therapy. Endocrine Practice 21 1111-1116. (doi:10.4158/EP15664.OR)

10 Alvarez L, Guanabens N, Peris P, Monegal A, Bedini JL, Deulofeu R, Martinez de Osaba MJ, Muñoz-Gomez J, Rivera-Fillat F \& Ballesta AM 1995 Discriminative value of biochemical markers of bone turnover in assessing the activity of Paget's disease. Journal of Bone and Mineral Research 10 458-465. (doi:10.1002/jbmr.5650100318)

Received in final form 20 January 2016

Accepted 25 January 2016 